\title{
Biosynthesis and application of silver nano-biotics for enhancing the antimicrobial activity of glass- ionomer cement against studied microorganisms and its effect on compressive strength
}

\section{Enas Tawfik Enan}

Taif University College of Science

Amal A. Ashour

Taif University College of Science

Sakeenabi Basha

Taif University College of Science

Nayef H. Felemban

Taif University College of Science

sanaa M. F. gad El-Rab ( $\sim$ sanaa1996@yahoo.com )

Taif University https://orcid.org/0000-0003-1872-6283

\section{Research article}

Keywords: Cupressus macrocarpa extract, AgNPs, antimicrobial activity, anti-biofilm, glass ionomer cement

Posted Date: August 29th, 2020

DOl: https://doi.org/10.21203/rs.3.rs-35758/v2

License: (c) (i) This work is licensed under a Creative Commons Attribution 4.0 International License.

Read Full License

Version of Record: A version of this preprint was published at Nanotechnology on March 3rd, 2021. See the published version at https://doi.org/10.1088/1361-6528/abe577. 


\section{Abstract}

Background. The development of dental caries is associated with various microorganisms and secondary caries formation is the main cause of restorations failure. The advise for restorative dental materials that have antimicrobial properties has stimulated the introduction of materials containing different antibacterial agents.

Objectives: Present study has been designed to synthesize silver nanoparticles (AgNPs) and incorporate AgNPs and amoxicillin into glass ionomer cement (GIC) to synergize its effect on oral microbes. The effect of the added antimicrobial agents on compressive strength (CS) of GIC was also evaluated.

Material and methods: Biosynthesis of AgNPs were done using Cupressus macrocarpa extract and AgNPs were charectatrized. A total of 120 disc-shaped specimens were prepared and classified into 4 main groups where Group A include conventional GIC, Groups B and C include GIC with AgNPs or Amoxicillin, respectively, while Group D included GIC with both AgNPs and Amoxicillin. Each group was tested for the antimicrobial activity against both Streptococcus mutans (S. mutans) and Staphylococcus aureus (S. aureus). The distribution of biofilm was examined via scanning electron microscope. The CS of the tested material was measured using a Material Test System(MTS).

Results: UV-Visible spectrum showed a peak of $429 \mathrm{~nm}$. TEM, XRD pattern and FTIR analysis confirmed the formation of AgNPs with spherical to oblong polydispersed particles of diameter in the range of 13.5$25.8 \mathrm{~nm}$. The maximum inhibitory zone was recorded for group $D$ against both tested bacteria with a mean of $29 \mathrm{~mm}$ at first 24-hour period to $15 \mathrm{~mm}$ at three weeks and showed antimicrobial rate $92.2 \%$ and $92.56 \%$, against both strains, respectively. Additionally, group D disintegrated the structure of $S$. aureus biofilm and even kill bacteria in the biofilms. Addition of AgNPs and Amoxicillin caused an insignificant effect on CS of GIC.

Conclusion: TheAgNPs showed a synergistic effect in combination with amoxicillin and GIC dental restorative material against studied microorganisms. The agents can be safely added with minimal effect on mechanical properties of the original cement.

\section{Introduction}

The oral cavity harbors an abundant number of pathogens that may cause different oral diseases. The development of dental caries and periodontal diseases is associated with various Gram-positive and Gram-negative microorganisms [1]. Secondary caries formation, at the margins of existing restorations, is the main cause of their failure. This can result from adhesion of cariogenic biofilms to the tooth or restoration surface with subsequent ingress of cariogenic bacteria, in absence of antibacterial cover by the restorative material [2]. Thus, restorative materials are preferred to have some unique properties such as fluoride release to prevent secondary caries, bactericidal or bacteriostatic effect, and tight bacterial seal [3]. Since their introduction to the markets, glass-ionomer cements (GICs) showed the most potent anticariogenic tendency among dental materials due to its fluoride releasing ability and remineralization 
potential $[4,5]$. The urge for restorative dental materials that have antimicrobial properties has stimulated the introduction of materials containing different antibacterial agents. Among the antimicrobials incorporated into the dental restorative material, the monomers 12-methacryloyloxydo- decylpyridinium bromide (MDPB), chlorhexidine digluconate (CHX), silver nanoparticles (AgNPs) and antibiotics are the most frequently used [5-8]. Although the addition of antibiotics to glass ionomer cement (GIC), may enhance its antibacterial effect, however, this may increase the possibility of developing antibiotic resistance [8]. A promising approach to the management of emerging bacterial resistance in dental restorative material is antibiotic formulated in nano-structures with dimensions of approximately 1 to $100 \mathrm{~mm}$ [9]. The newly designed formulations are known as nano-antibiotics or nanobiotics. Silver nanoparticles (AgNPs) are most extensively tested inorganic antimicrobial agents due to their long term antibacterial activity, low bacterial resistance, low volatility, high surface to volume ratio and high thermal stability $[10,11]$. The exact mechanism how the AgNPs act is unknown. However, studies have shown that, because of their nano size, silver particles penetrate the microbial cell wall/cell membranes by sulfer-containing proteins or thiol groups and damages the microbial DNA and ultimately leads to cell death $[11,12]$. Studies have shown, AgNPs synergize the efficacy of antibiotics like amoxicillin, clindamycin, vancomycin and penicillin $G$ against various microbes $[13,14]$. Because of its antimicrobial activity and synergizing effects, researchers have studied the use of AgNPs in several areas of dentistry which include dental biomaterials [15-17], dental implants [18], orthodontic adhesives [19] etc. In vitro studies have shown, addition of AgNPs in to dental restorative materials inhibit growth of common oral microbes like Streptococcusmutans, Streptococcus sanguinis, and Lactobacillus through bactericidal and bacteriostatic effects of AgNPs on oral microbes $[16,20]$ without altering its mechanical properties [21]. With growing bacterial resistance to amoxicillin $[22,23]$, commonly used antibiotic in oral infection and synergistic effect of AgNPs with amoxicillin and its antimicrobial effect on oral microbes were studied. The present study has been designed to assess the synergistic effect of silver nano-biotics incorporated into glass ionomer against oral microbes.

\section{Material And Methods}

Materials

The current study was performed using one restorative material, conventional GIC Fuji IX GP (powder/liquid form), GC Corporation (Tokyo, Japan,) and two antimicrobial agents, silver nanoparticles and Amoxicillin (1.5\% w/w) antibiotic. AgNPs were biosynthesized using Cupressus macrocarpa extract at a particle size of $<100 \mathrm{~nm}$. The Silver nano - powder was weighed on a balance accurate to $0.0001 \mathrm{~g}$ (TS4000, Ohaus, Pine Brook, NJ, USA) and mixed with GIC powder in a percentage of $0.5 \%(\mathrm{w} / \mathrm{w})$ immediately prior to manipulation. For GIC manipulation, the same amount of powder was removed to add AgNP and/or amoxicillin. Two species of bacteria, S.mutans and S. aureus, were isolated from medical diagnosis and infection control unit, Faculty of Dentistry, Taif University.

Methods 


\section{Preparation of specimens and grouping}

A total of 120 disc-shaped specimens were prepared for the study using a split Teflon mold $(6 \mathrm{~mm}$ in diameter and $3 \mathrm{~mm}$ in height) [24]. All specimens were prepared at room temperature $\left(24^{\circ} \mathrm{C}-27^{\circ} \mathrm{C}\right)$, in $70 \%$ relative humidity. GIC powder and liquid were proportioned and mixed with a plastic spatula, as recommended by the manufacture, and placed in the molds. The molds were covered on both sides by polyester strips and thick glass plates and allowed to set for $20 \mathrm{~min}$ after which they were removed from the mold, sterilized for 30 min using ultraviolet radiation and stored at $37^{\circ} \mathrm{C}$ for 1 hour in sterilized distilled water before testing. Malformed or large voids containing specimens were discarded, The prepared specimens $(n=120)$ were classified into 4 main groups (30 specimens each) as follows:

Group A (control), conventional GIC without any addition

Group B, GIC with AgNPs

Group C, GIC with Amoxicillin

Group D, GIC with AgNPs and Amoxicillin

Then each of the main groups was tested for the antimicrobial effect against 2 types of bacterial species, S. mutans and $S$. aureus, at three time intervals of 1 day, 1 week and 3 weeks. During the testing intervals, the specimens were stored in distilled water at $37^{\circ} \mathrm{C}$.

\section{Preparation of Cupressus macrocarpa extract and Biosynthesis of AgNPs}

The fresh and healthy leaves of Cupressus macrocarpa plant plant from Taif region were collected and were washed with distilled water and aqueous extract was prepared $\left(25 \mathrm{~g} / 100 \mathrm{ml} \mathrm{H}_{2} \mathrm{O}\right)$ at $85^{\circ} \mathrm{C}$ for $60 \mathrm{~min}$. The extract was filtered and the filtrate was stored at $4{ }^{\circ} \mathrm{C}$ for further experiments as reducing agent and stabilizer, being usable for within 2 weeks [25]. Fifty $\mathrm{mL}$ of $1 \mathrm{mM} \mathrm{AgNO}_{3}$ was added to $25 \mathrm{~mL}$ of aqueous extract and mixed on a magnetic stirrer. The thorough mixing of reaction mixture was ensured by vigorous shaking and then allowed to settle at room temperature. The change in color to dark brown from pale yellow confirmed AgNPs formation [26].

Characterization of AgNPs:

\section{UV-visible spectral analysis}

UV-vis spectrometer (Shimadzu UV-1650) was used to record absorbance in the range of 300-700 nm. The UV-vis absorption spectroscopy was used to monitor the rate of AgNPs.

\section{Transmission electron microscopy (TEM) particle size analysis}


Characterization of AgNPswas studied using TEM analysis. The size and morphology of the nanoparticles were measured with high resolution TEM (JEOL 100CX II with an accelerating voltage of $100 \mathrm{kV}$, at Assiut Electron Microscope Unit) [27].

\section{X-ray Diffraction analysis}

The AgNPs nature and size were determined using Shimadzu XRD (Shimadzu XD-3A, Japan). The AgNPs size was calculated using the formula of Debye-Scherrer [28].

\section{Fourier transform infrared analysis (FTIR)}

FT-IR spectrum was obtained using a Shimadzu IR-470 Spectrometer (Shimadzu, Japan) in the range of 500-4000 cm-1[29].

\section{Assessing the antimicrobial activity}

The antimicrobial activity of each specimen in testing groups against oral pathogenic microorganisms; $S$. aureus, and $S$. mutans were tested based on Kirby-Bauer method [30]. The aerobic $S$. aureus and an aerobic S. mutans were grown in Mueller Hinton agar ( $\mathrm{MH}-\mathrm{A})$ or brain heart infusion (BHI-A), respectively at $37^{\circ} \mathrm{C}$ for $24 \mathrm{~h}$. The antimicrobial activity of the samples was evaluated by determining the diameter of the clear zone of inhibition around the specimen discs. All samples were done in triplicate.

\section{Determination of antibacterial effect rate (\%)}

Each specimen of the groups was placed in a 15-mm diameter glass bottles with a flat bottom surface. One specimen of each group were put and incubated in $0.5 \mathrm{ml}$ of $S$. aureus or $S$. mutans suspension of 1 $\times 10^{6}$ cells $/ \mathrm{ml}$ in broth growth medium $\mathrm{MH}-\mathrm{B}$ and $\mathrm{BHI}-\mathrm{B}$, respectively for regular interval of times at $37^{\circ} \mathrm{C}$. The control sample, $0.5 \mathrm{ml}$ bacterial suspension of $1 \times 10^{6}$ cells $/ \mathrm{ml}$ in broth media was incubated without specimens. After incubation, each sample was washed gently with distilled water and immediately transferred into $10 \mathrm{ml}$ phosphate buffer. Each $100 \mu \mathrm{l}$ of sample was platted on a Mueller Hinton agar or brain heart infusion (BHI) plate, respectively, spread evenly and incubated at $37^{\circ} \mathrm{C}$ for $24 \mathrm{~h}$, finally, the number of colonies (colony-forming unit: CFU) were counted. Antibacterial activity was expressed as the logarithm of CFUs on each specimen. Each colonization test was run in triplicate and repeated at five separate times. The antibacterial effect in each group was calculated as a bactericidal ratio, which was calculated as follows: $\mathrm{AE}=\mathrm{C}-\mathrm{T} / \mathrm{C} \times 100$ where $\mathrm{AE}$ is an antibacterial rate (\%), $\mathrm{C}$ is the number of the bacteria in the control sample (CFU/sample), and $\mathrm{T}$ is the number of bacteria in the testing samples (CFU/sample).

\section{Characterization of bacterial morphology and anti-biofilm activity of restorative biomaterials by SEM}

The $S$. aureus morphology and anti-biofilm activity of restorative biomaterials were determined using the protocol given by Souza et al [31]. with some modifications. In brief, each specimen of the restorative biomaterial groups was placed in 24-well plates containing $2 \mathrm{~mL}$ of $\mathrm{MH}-\mathrm{B}$ with $5 \%$ Sucrose and $0.1 \mathrm{~mL}$ of human saliva. The 24 -well plates were subsequently incubated at $37^{\circ} \mathrm{C}$ under aerophilic conditions.After 
incubation, each sample was washed gently with distilled water. Scanning electron microscopy (SEM) of each sample with bacterial biofilm was immediately fixed in cold glutaraldehyde for 2 hours, fixed in the solution of osmium tetroxide ( $2 \%$ ) for 2 hours, dehydrated in serial ascending ethanol and finally, dried using liquid $\mathrm{CO}_{2}$. For $\mathrm{SEM}$, samples were mounted on stainless steel holders, sputter-coated with a thin layer of gold (22) and examined by JOEL SEM (JSM-5400LV). SEM examinations of samples were analyzed. Five specimens were examined for each group.

\section{Measurement of compressive strength}

Cylindrical specimens, of $4 \mathrm{~mm}$ diameter and $6 \mathrm{~mm}$ height, were prepared using a teflon mold to test the compressive strength. Each specimens was allowed to set at room temperature for 20 minutes before its removal from the mold. Compressive strength (CS) of set cement was measured after $24 \mathrm{~h}$ of mixing using a Material Test System (810 MTS Co., Minneapolis, MN, USA) for all groups at a crosshead speed of $0.5 \mathrm{~mm} / \mathrm{min}$ [21]. Ten specimens were tested for each group. The flat end of the specimens were positioned between the MTS machine plates to apply the progressively increasing compressive load along the long-axis of specimen. The force-displacement curve was measured using LJ stream software. The maximum recorded force at the fracture was taken and $\mathrm{CS}\left(\mathrm{N} / \mathrm{mm}^{2}\right)$ was recorded using the following equation.

$\mathrm{CS}=4 \mathrm{P} / \pi \mathrm{d}^{2}$

$d$ represents the diameter of the specimen and $P$ represents the failure load.

\section{Statistical analysis}

Descriptive summary statistics were obtained for all independent and outcome variables. Difference in mean was tested using analysis of variance (ANOVA) followed by Tukey's post hoc and t-test. Analysis was performed using the Statistical Package for Social Science version 17 (SPSS INC Chicago link). All statistical tests were two-sided, and the significance level was set at $p<0.05$.

\section{Result And Discussion}

Biosynthesis of AgNPs:

Biosynthesis of AgNPs include the use of microorganism, plant extract and enzymes [32,33]. Plant parts like flowers, fruits, stems, leaves, etc. are widely used in the biosynthesis of AgNPs because of its low cost, less time in processing and can be done on a small to large scale basis [32-34]. The morphology, stability and size of AgNPs formed depend on the method of its preparation, nature of the solvent used, temperature and strength of the reducing agent. On this study, AgNPs were biosynthesized using aqueous Cupressus macrocarpa extract because it contains reducing stabilizing agents [35, 36]. In the present study formation of AgNPs was indicated by a change in color from pale yellow to dark brown (Figure 1-IA). This is due to the fabrication of AgNPs with the molecular assistance of biological reducing agents present in the Cupressus macrocarpa extract. AgNPs showed brown color in aqueous solution due to the 
excitation of surface plasmon vibrations [26]. At lower concentrations of leaf extract, slower reduction was observed and vise versa. For $10 \%$ extract, fast reduction occurred as indicated by brown to dark brown color of the solution.

Characterization of AgNPs:

UV-Vis spectroscopy of AgNPs: For the confirmation of nanoparticles-formation, in the present study, the samples were removed and analyzed at regular time intervals using UV-Visible-spectroscopy. It was noticed that the complete color change took about $24 \mathrm{~h}$, there after no further color of the reaction mixture changed. This indicated that $\mathrm{AgNO}_{3}$ solution present in the reaction mixture has been reduced completely. AgNPs showed peaks at $429 \mathrm{~nm}$ as shown in (Figure 1-I-B). The UV-visible peak at $429 \mathrm{~nm}$ was for pure AgNPs. After complete incubation, AgNPs were centrifuged at $15,000 \mathrm{~g}$ for $30 \mathrm{~min}$ followed by washing with MilliQ water. However, ethanol $(50 \% \mathrm{~V} / \mathrm{V})$ was used to remove excess extract from the sample and this sample was kept at room temperature till further characterization. The study by Beg et al. [37] showed biosynthesis of AgNPs from seed extract of Pongamia pinnata had an absorption peak of $439 \mathrm{~nm}$. The study by Vijaykumar et al. [38] showed an absorption maximum at 418 under Boerhaavia diffusa plant extract biosynthesis of AgNPs. Slight variation in absorption peak may be attributed to different quantities of the reducing chemicals present in the extracts.

\section{Transmission Electron Microscope analysis (TEM)}

The AgNPs were characterized using TEM analysis (Figure1-II). Average size of AgNPs was estimated to be at 13.5-25.8 nm. TEM analysis showed that all these AgNPs were of spherical to oblong polydispersed shape which supports the dispersion and stability of AgNPs with Cupressus macrocarpa extract. The successive Cupressus macrocarpa extract obtained was displayed various phytoconstituents. It revealed the presence of different phytoconstituents like glycosides, carbohydrates, flavonoids, amino acid, phenolics, saponin, protein and sterols in the extracts [39].

$X$-ray Diffraction analysis

In the present study, X-ray Diffraction (XRD) pattern showed four major peaks at $2 \theta$ values of $38^{\circ}, 47^{\circ}$, $55^{\circ}$ and $73^{\circ}$. These characteristic peaks could be attributed to reflection planes (111), (200), (220) and (311) of face-centred cubic crystalline (FCC) structure of pure metallic silver (Figure 1-III).

\section{Comparison of FTIR spectra of Cupressus macrocarpa extract and AgNPs}

Fourier transform infrared analysis (FTIR) was used to characterize the Cupressus macrocarpa extract and the resulting AgNPs. Absorbance bands observed in the region 500 to $4000 \mathrm{~cm}^{-1}$ and approximately 1053, 1257, 1401, 1570, 1622, 2924, 3380 and $3459 \mathrm{~cm}^{-1}$ as shown in Figure IV-A and Table 1. FTIR analysis further confirmed the presence of functional groups representing bioactive compounds of Cupressus macrocarpa through the absorption bands at $3459 \mathrm{~cm}^{-1}$, implying Broad $\mathrm{H}$-bonded-OH stretching, $1622 \mathrm{~cm}^{-1}$, denoting amide group, $1401 \mathrm{~cm}^{-1}$, representing methylene -CH bending bond, 1257 
$\mathrm{cm}^{-1}$, representing phenol/C-O- stretching bond and $1053 \mathrm{~cm}^{-1}$ of primary alcohol/C-O- stretching as shown in Figure IV-A. Cupressus macrocarpa extract caused a reduction of silver ions. In the absorbance intensities at $3380 \mathrm{~cm}^{-1}$, representing $\mathrm{OH}$ stretching. Absorbance peak at $1622 \mathrm{~cm}^{-1}$ (amide group), 1401 $\mathrm{cm}^{-1}$ (methylene - $\mathrm{CH}$ bending), $1257 \mathrm{~cm}^{-1}$ (phenol/C-O- stretching), $1053 \mathrm{~cm}^{-1}$ (primary alcohol/C-O) and $543 \mathrm{~cm}^{-1}(-\mathrm{CH}-$ stretch) have shown that organic compounds in the plant extract have reduced and stabilized AgNPs, thereby preventing agglomeration (Figure IV-B and Table 1). The bands at $1257 \mathrm{~cm}^{-1}$ and smaller peaks at 1053 and $750 \mathrm{~cm}-1$ could be assigned to the stretching vibrations of $\mathrm{C}-\mathrm{N}, \mathrm{C}-\mathrm{O}$ and $=\mathrm{C}-\mathrm{H}$, respectively. Additionally, the regions from 600 to $500 \mathrm{~cm}^{-1}$ were due to the $\mathrm{C}-\mathrm{O}$ and $\mathrm{C}-\mathrm{C}$ groups' vibration modes. The reduction is due to the previous bands presented in Cupressus macrocarpa extract as shown in (Figure IV and Table 1). Cupressus macrocarpa extract contains saponins, phenolic compounds and carbohydrates as reported by Thukralet al. [39] and these components react as reducing and stabilizing agents. For this reason, we used Cupressus macrocarpa in biosynthesis of AgNPs.

\section{Antimicrobial activity}

Antimicrobial activity of biomaterial against $S$. mutans and $S$. aureus is presented in Figure 2 and Table 2 . Twenty-four hour inhibition zone for the $S$. mutans and $S$. aureus was highest $(29 \pm 1.14$ for $S$. muatns and $30 \pm 2.7$ for $S$. aureus) for Group D with GIC,AgNPs and amoxicillin combination compared to other groups (Table 2). Group B with GIC and AgNPs combination showed significantly high inhibitory zone against both the bacteria compared to Group $A$ and Group $C$ in twenty-four hour and one week inhibitory zone (Table 2). Present study results are in line with the previously conducted studies $[13,14,16,20]$ which have confirmed the synergistic effect of AgNPs against microbes in combination with antibiotics. Present study showed mean inhibitory zone, which was significantly higher for $S$. aureus compared to S. mutans (Table 3). However, specific response of each bacterium depended on their metabolic characteristics. These results come in agreement with the study conducted by Ortiz et al. [40] who showed that the most sensitive bacteria to AgNPs alone was $S$. aureus and the most resistant microorganisms were $S$. mutans in which no inhibition halo was generated. Additionally, Cupressus macrocarpa extract has strong anti-inflammatory and antibacterial properties, and these functions will

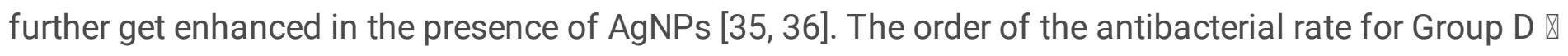
Group B $\otimes$ Group $C \otimes$ Group A was observed in Figure 3 and Table 4. Group D ensured $92.2 \%$ and $92.56 \%$ inhibition of $S$. aureus or $S$. mutant respectively. The inhibition of CFU in GIC supplemented with AgNPs (Group B) was higher compared to the GIC alone (Group A) and the GIC with amoxicillin (Group C) (Figure $3)$.

\section{Characterization of bacterial morphology and anti-biofilm activity}

The occurrence of $S$. aureus in the oral cavity of patients with dental caries was confirmed in previous study recorded by Vellappally et al. [41] so, we studied the antibiofilm efficacy on $S$. aureus biofilm using SEM (Figure 4). The efficacy of group $A$ and group $C$ on culture appeared as aggregated and clumped cell mass with normal cellular morphology. In sample of group B, slightly changes in cell morphology were seen. In group D high anti-biofilm efficacy and changes were seen including the lack of bacterial cell 
adhesion as well as cells misshapen and damaged membrane (Figure 4). This suggest, combination of AgNPs with GIC and Amoxicillin can disintegrate the structure of biofilm and even kill bacteria in the biofims [42].

Present study results revealed that AgNPs and amoxicillin with GIC (group D) was more effective against $S$. aureus or $S$. mutans because it initially induced aggregates in the cell envelopes of $S$. aureus or $S$. mutans and eventually caused cell lyses [43]. In synergism, the bactericidal efficacy is enhanced by chelation between active groups like hydroxyl and amino groups present in these antibiotics with AgNPs. As reporting by Krishna et al., [44] antibiotic-silver nanoparticles conjugate is formed in which a AgNPs core is surrounded by antibiotic molecules. Thus, the antimicrobial concentration is increased at the focal site, which leads to increased destruction of bacteria.

The microbiological study confirmed that group D has high antimicrobial activity. In the other hand, our study in Part B, recorded that AgNPs did not affect the mechanical property of GIC (Data not shown) and this was recorded in previous study by El-Wassefy et al [45].

Compressive strength of tested materials: Effect of AgNPs addition on physical properties of modified GIC was tested using compressive strength measurement. The results showed a minor increase in compressive strength of specimens that were modified with silver nanoparticles (groups B and D) (Table 5). On the other hand, the addition of antibiotic particles to GIC caused a sligth decrease of its compressive strength. The difference between all groups was statistically insignificant $(P=0.07)$. The effect of AgNPs may be attributed to their anchoring effect when distributed in the cement matrix, which helped to increase the cohesive strength of GIC. [15] Though, our results showed that the reinforcing effect of AgNPs was insignificant, which can be explained by the fact that the nono-particles in the present study were physically added to the cement, so they were not firmly bonded to the matrix and did not alter the mechanical properties significantly. [21]

The current results came in agreement with those of Paiva et al. [15] who concluded a reinforcing effect of AgNPs on the compressive strength of GIC, but their results showed a significant change. On the other hand, a study by El-Wassefy et al., [21] showed that AgNPs added to GIC decreased the material's strength, but the effect was insignificant. The difference between the current results and others may be related to differences in the tested materials and the applied methodology

\section{Conclusion}

To conclude Cupressus macrocarpa extract bio-synthesized AgNPs showed good characterization and stability. It showed synergistic antimicrobial and anti-biofilm activity when combined with amoxicillin and GIC dental material. The excellent antibacterial results of AgNPs and amoxicillin with GIC make authors strongly recommend them as a relevant combination for dental application. The insignificant impact of the added antimicrobial agents on compressive strength of GIC encourages their application with minimal effect on mechanical properties of the original cement. 


\section{Declarations}

\section{Conflict of interest:}

The authors declare that they have no conflict of interest.

\section{Acknowledgment}

We would like to express our gratitude to Taif University for financial support, under the project number $(1 / 439 / 6084)$.

\section{References}

1. Mira A, Simon-Soro A, Curtis MA. Role of microbial communities in the pathogenesis of periodontal diseases and caries. J Clin Periodontol. 2017;44:S23-S38.

2. Askar H, Brouwer F, Lehmensiek M, Paris S, Schwendicke F. The association between loading of restorations and secondary caries lesions is moderated by the restoration material elasticity. J Dent. 2017;58:74-9.

3. doAmaralGS, Negrini T, Maltz M, Arthur RA. Restorative materials containing antimicrobial agents: is there evidence for their antimicrobial and anticaries effects? A systematic review. Aust Dent J. 2016 Mar;61(1):6-15.

4. Xie D, Weng Y, Guo X, et al. Preparation and evaluation of a novel glass-ionomer cement with antibacterial functions. Dent Mater. 2011;27(5):487-96.

5. Imazato S, Kinomoto $\mathrm{Y}$, Tarumi H, Ebisu S, Tay FR. Antibacterial activity and bonding characteristics of an adhesive resin containing antibacterial monomer MDPB. Dent Mater. 2003;19:313-9.

6. Duque C, Aida KL, Pereira JA, et al. In vitro and in vivo evaluations of glass-ionomer cement containing chlorhexidine for Atraumatic Restorative Treatment. J Appl Oral Sci. 2017t;25(5):541-50.

7. Sundeep D, Vijaya Kumar T, Rao PSS, Ravikumar RVSSN, Gopala Krishna A. Green synthesis and characterization of Ag nanoparticles from Mangiferaindica leaves for dental restoration and antibacterial applications. Prog Biomater. 2017;6(1-2):57-66.

8. Pinheiro SL, Simionato MR, Imparato JC, Oda M. Antibacterial activity of glassionomer cement containing antibiotics on caries lesion microorganisms. Am J Dent. 2005;18:261-6.

9. Allaker RP. The use of nanoparticles to control oral biofilm formation. J Dent Res. 2010;89:1175-86.

10. Monowar T, Rahman MS, Bhore SJ, Raju G, Sathasivam KV. Silver Nanoparticles Synthesized by Using the Endophytic Bacterium Pantoeaananatis are Promising Antimicrobial Agents against Multidrug Resistant Bacteria. Molecules. 2018;6:23(12).

11. Jaiswal S, Mishra P. Antimicrobial and antibiofilm activity of curcumin-silver nanoparticles with improved stability and selective toxicity to bacteria over mammalian cells. Med Microbiollmmunol. 
2018;207(1):39-53.

12. Quinteros MA, Viviana CA, Onnainty R, et al. Bio-synthesized silver nanoparticles: Decoding their mechanism of action in Staphylococcus aureus and Escherichia coli. Int J Biochem Cell Biol. 2018;104:87-93.

13. Ghosh S, Patil S, Ahire M, et al. Synthesis of silver nanoparticles using dioscoreabulbifera tuber extract and evaluation of its synergistic potential in combination with antimicrobial agents. Int $\mathrm{J}$ Nanomed. 2012;7:483-96.

14. Hwang IS, Hwang JH, Choi H, Kim KJ, Lee DG. Synergistic effects between silver nanoparticles and antibiotics and the mechanisms involved. J Med Microbiol. 2012;61:1719-26.

15. Paiva L, Fidalgo TKS, da Costa LP, et al. Antibacterial properties and compressive strength of new one-step preparation silver nanoparticles in glass ionomer cements (NanoAg-GIC). J Dent. 2018;69:102-9.

16. Azarsina M, Kasraei S, Yousef-Mashouf R, Dehghani N, Shirinzad M. The antibacterial properties of composite resin containing nanosilver against Streptococcus mutans and Lactobacillus. J Contemp Dent Pract. 2013;14(6):1014-8.

17. Bapat RA, Chaubal TV, Joshi CP, et al. An overview of application of silver nanoparticles for biomaterials in dentistry.Mater SciEng. C Mater Biol Appl. 2018;91:881-98.

18. Divakar DD, Jastaniyah NT, Altamimi HG, et al. Enhanced antimicrobial activity of naturally derived bioactive molecule chitosan conjugated silver nanoparticle against dental implant pathogens. Int $\mathrm{J}$ BiolMacromol. 2018;108:790-7.

19. Sodagar A, Akhavan A, Hashemi E, et al. Evaluation of the antibacterial activity of a conventional orthodontic composite containing silver/hydroxyapatite nanoparticles. ProgOrthod. 2016;17(1):40.

20. Panpaliya NP, Dahake PT, Kale YJ, et al. In vitro evaluation of antimicrobial property of silver nanoparticles and chlorhexidine against five different oral pathogenic bacteria. Saudi Dent $J$. 2019;31(1):76-83.

21. El-Wassefy NA, El-Mahdy RH, El-Kholany NR. The impact of silver nanoparticles integration on biofilm formation and mechanical properties of glass ionomer cement. J EsthetRestor Dent. 2018;30:146-52.

22. Loyola-Rodriguez JP, Ponce-Diaz ME, Loyola-Leyva A, et al. Determination and identification of antibiotic-resistant oral streptococci isolated from active dental infections in adults. Acta Odontol Scand. 2018;76(4):229-35.

23. Loyola-Rodriguez JP, Garcia-Cortes JO, Martinez-Martinez RE, et al. Molecular identification and antibiotic resistant bacteria isolated from primary dentition infections. Aust Dent J. 2014;59(4):497503.

24. Felemban NH, Ebrahim Ml. Effects of adding silica particles on certain properties of resin-modified glass-ionomer cement. Eur J Dent. 2016;10(2):225-9.

25. Lee SH, Salunke BK, Kim BS. Sucrose density gradient centrifugation separation of gold and silver nanoparticles synthesized using Magnolia Kobus plant leaf extracts. Biotech Bioprocess Engin. 
2014;19:169-74.

26. Oliveira GZS, Lopes CAP, Sousa MH, Silva LP. Synthesis of silver nanoparticles using aqueous extracts of Pterodonemarginatus leaves collected in the summer and winter seasons. International Nano Letters. 2019;9:109-17.

27. Hussein-Al-Ali SH, El Zowalaty ME, Hussein MZ, Ismail M, Webster TJ. Synthesis, characterization, controlled release, and antibacterial studies of a novel streptomycin chitosan magnetic nanoantibiotic. Inter J of Nanomedicine. 2014;9:549-57.

28. Dubey SPL, LahtinenM,Sillanpaa M. Tansy fruit mediated greener synthesis of silver and gold nanoparticles. Process Biochem. 2010;45:1065-71.

29. Panigrahi AK. Relationship between Inventory Management and Profitability: An Empirical Analysis of Indian Cement Companies. Asia Pac J Marketing Management Review. 2013;2(7).

30. Hudzicki J. Kirby-Bauer Disk Diffusion Susceptibility Test Protocol. American Society of Microbiology. 2016.

31. Souza JCM, Mota RRC, Sordi MB, Passoni BB, Benfatti CAM, Magini RS. Biofilm Formation on Different Materials Used in Oral Rehabilitation. Brazilian Dental Journal. 2016;27(2):141-7.

32. Song JY, Kim BS. Rapid biological synthesis of silver nanoparticles using plant leaf extracts. Bioprocess Biosyst Eng. 2009;32(1):79-84.

33. Gurunathan S, Kalishwaralal K, Vaidyanathan R, Venkataraman D, Pandian SR, Muniyandi J, Hariharan N, Eom SH. Biosynthesis, purification and characterization of silver nanoparticles using Escherichia coli. Colloids Surf B Biointerfaces. 2009;74(1):328-35.

34. Thukral SK, Singh S, Sharma S. Pharmacognostical standardization of leaves of Cupressus macrocarpaHartweg. ex Gordon. Journal of Applied Pharmaceutical Science. 2004;4(05):071-4.

35. Salem MZM1, Elansary HO, Ali HM. et al. Bioactivity of essential oils extracted from Cupressusmacrocarpabranchlets and Corymbiacitriodora leaves grown in Egypt. BMC Complement Altern Med. 2018;18(1):23.

36. Teke GN, Elisée KN, Roger KJ. Chemical composition, antimicrobial properties and toxicity evaluation of the essential oil of Cupressus/usitanica Mill leaves from Cameroon. BMC Complement Altern Med. 2013;13:130.

37. Beg M, Maji A, Mandal AK, et al. Green synthesis of silver nanoparticles using Pongamiapinnata seed: Characterization, antibacterial property, and spectroscopic investigation of interaction with human serum albumin. J Mol Recognit. 2017;30(1).

38. Vijay Kumar PPN, Pammi SVN, PratapKollu, Satyanarayana KVV, Shameem U. Green synthesis and characterization of silver nanoparticles using Boerhaaviadiffusa plant extract and their anti bacterial activity. Industrial Crops Product. 2014;52:562-6.

39. Thukral SK, Singh S, Kr Sharma S. Pharmacognostical standardization of leaves of Cupressus macrocarpaHartweg. ex Gordon. J Appl Pharma Sci. 2014;4:071-4. 
40. Ortiz EP, Ruiz JHR, Márquez EAH, et al. Dose-Dependent Antimicrobial Activity of Silver Nanoparticles on Polycaprolactone Fibers against Gram-Positive and Gram-Negative Bacteria. J Nanomaterials. 2017.

41. Vellappally S, Divakar DD, Al Kheraif AA, Ramakrishnaiah R, Alqahtani A, Dalati MHN, Anil S, Khan AA, Varma HPR. Occurrence of vancomycin-resistant Staphylococcus aureus in the oral cavity of patients with dental caries. Acta Microbiologica et ImmunologicaHungarica. 2017;64(3):343-51.

42. Ananda AP, Manukumar HM, Krishnamurthy NB, Nagendra BS, Savitha KR. Assessment of antibacterial efficacy of a biocompatible nanoparticle PC@ AgNPs against Staphylococcus aureus. Microb Pathog. 2019;126:27-39.

43. Fayaz AM, Balaji K, Girilal M, Yadav R, KalaichelvanPT,Venketesan R. Biogenic synthesis of silver nanoparticles and their synergistic effect with antibiotics: a study against gram-positive and gramnegative bacteria. Nanomedicine. 2010;6:103-9.

44. Krishna G, Kumar SS, Pranitha V, Alha M, Charaya S. Biogenic synthesis of silver nanoparticles and their synergistic effect with antibiotics: A study against Salmonella SP. International Journal of Pharmacy Pharmaceutical Sciences. 2015;7(10):84-8.

45. El-Wassefy NA, El-Mahdy RH, El-Kholany NR. The impact of silver nanoparticles integration on biofilm formation and mechanical properties of glass ionomer cement. J EsthetRestor Dent. 2018;30:146-52.

\section{Tables}

Table 1. Peaks obtained by FTIR analysis and corresponding functional groups.

\begin{tabular}{|llll|}
\hline Plant extract & & AgNPs & \\
\hline Peak $\left(\mathrm{cm}^{-1}\right)$ & Functional group & Peak $\left(\mathrm{cm}^{-1}\right)$ & Functional group \\
\hline 3459 & Broad H-bonded-OH stretching & 3380 & broad -OH bending \\
\hline 1622 & amide $/$-NH bending & 1622 & amide group \\
\hline 1401 & -CH bending & 1401 & methylene - $\mathrm{CH}$ bending \\
\hline 1257 & phenol/C-O- stretching & 1257 & phenol/C-O- stretching \\
\hline 1053 & primary alcohol/C-O- stretching & 1053 & C-O stretch/primary alcohol \\
\hline
\end{tabular}

Table 2: Antimicrobial activity of biomaterial against Streptococcus mutans and Staphylococcus aureus at different times 


\begin{tabular}{|c|c|c|c|}
\hline & \multicolumn{3}{|l|}{ Inhibition zone } \\
\hline & $\ln Z$ & $\ln Z$ & $\operatorname{lnz}$ \\
\hline & $24 \mathrm{~h}$ & 1 Week & 3 Week \\
\hline \multicolumn{4}{|c|}{ Streptococcus mutans } \\
\hline Group A (n =5) & $8 \pm 1.14$ & 0 & 0 \\
\hline Group B $(n=5)$ & $18 \pm 2.5$ & $13.8 \pm 0.83$ & $11 \pm 0.84$ \\
\hline Group C $(n=5)$ & $8 \pm 0.7$ & 0 & 0 \\
\hline Group D $(n=5)$ & $29 \pm 1.14$ & $20 \pm 1.14$ & $15 \pm 1.04$ \\
\hline ANOVA, $F$ value & 18.17 & 19.44 & 11.32 \\
\hline ANOVA, $P$ value & 0.0001 & 0.0001 & 0.03 \\
\hline Tukey post Hoc & $\begin{array}{l}d>a, d>c, d>b, b>c \\
b>a\end{array}$ & $\begin{array}{l}d>a, d>c, d>b, b>c \\
b>a\end{array}$ & $d>b$ \\
\hline \multicolumn{4}{|l|}{$\begin{array}{l}\text { Staphylococcus } \\
\text { aureus }\end{array}$} \\
\hline Group A (n =5) & $9 \pm 1.04$ & 0 & 0 \\
\hline Group B $(n=5)$ & $20 \pm 1.2$ & $14.8 \pm 1.28$ & $12 \pm 1.2$ \\
\hline Group C (n=5) & $9 \pm 1.28$ & 0 & 0 \\
\hline Group D $(n=5)$ & $30 \pm 2.7$ & $23 \pm 1.9$ & $16 \pm 2.1$ \\
\hline ANOVA, $F$ value & 19.47 & 13.6 & 10.58 \\
\hline ANOVA, $P$ value & 0.0001 & 0.001 & 0.04 \\
\hline Tukey post Hoc & $\begin{array}{l}d>a, d>c, d>b, b>c \\
b>a\end{array}$ & $\begin{array}{l}d>a, d>c, d>b, b>c, \\
b>a\end{array}$ & $\begin{array}{l}d>b, d>a, d>c, b>c, \\
b>a\end{array}$ \\
\hline
\end{tabular}

Table 3: Comparison of Mean (SD) inhibitory zone of material used against Streptococcus mutansand Staphylococcus aureus. 


\begin{tabular}{|c|c|c|c|c|}
\hline \multicolumn{4}{|c|}{ Bacteria used } & \multirow[t]{2}{*}{ t test, $P$ value } \\
\hline Study groups & $\begin{array}{l}\text { Inhibitory } \\
\text { zone }\end{array}$ & $\begin{array}{l}\text { Streptococcus } \\
\text { mutans, }\end{array}$ & $\begin{array}{l}\text { Staphylococcus } \\
\text { aureus }\end{array}$ & \\
\hline \multirow{3}{*}{$\begin{array}{l}\text { Group A (n } \\
=5)\end{array}$} & 24 hour & $8 \pm 1.14$ & $9 \pm 1.04$ & 0.03 \\
\hline & 1 week & 0 & 0 & NA \\
\hline & 3 week & 0 & 0 & NA \\
\hline \multirow{3}{*}{$\begin{array}{l}\text { Group B (n } \\
=5 \text { ) }\end{array}$} & 24 hour & $18 \pm 2.5$ & $20 \pm 1.2$ & 0.06 \\
\hline & 1 week & $13.8 \pm 0.83$ & $14.8 \pm 1.28$ & 0.09 \\
\hline & 3 week & $11 \pm 0.84$ & $12 \pm 1.2$ & 0.08 \\
\hline \multirow{3}{*}{$\begin{array}{l}\text { Group C (n } \\
=5)\end{array}$} & 24 hour & $8 \pm 0.7$ & $9 \pm 1.28$ & 0.03 \\
\hline & 1 week & 0 & 0 & NA \\
\hline & 3 week & 0 & 0 & NA \\
\hline \multirow{3}{*}{$\begin{array}{l}\text { Group D ( } \\
=5)\end{array}$} & 24 hour & $29 \pm 1.14$ & $30 \pm 2.7$ & 0.07 \\
\hline & 1 week & $20 \pm 1.14$ & $23 \pm 1.9$ & 0.08 \\
\hline & 3 week & $15 \pm 1.04$ & $16 \pm 1.03$ & 0.03 \\
\hline
\end{tabular}

Group A- control (glass inomer alone), Group B- Gi + AgNPs, Group C - Gi + Amoxicillin, Group D Gi+AgNPs+Amoxicillin, NA - Not applicable.

Table 4. Logarithm of average CFU count (log CFU) and antibacterial rate (R) of specimens against streptococcus mutans and Staphylococcus aureus. 


\begin{tabular}{|c|c|c|c|c|c|c|}
\hline & \multicolumn{2}{|l|}{ S.mutans } & \multirow[t]{2}{*}{ ANOVA } & \multicolumn{2}{|l|}{ S. aureus } & \multirow{2}{*}{$\begin{array}{l}p \\
\text { value, } \\
\text { ANOVA }\end{array}$} \\
\hline & Log CFU & $R(\%)$ & & Log CFU & $R(\%)$ & \\
\hline A & 8.98 & 3.03 & 0.1 & 8.95 & 13.13 & 0.17 \\
\hline B & 8.75 & 42.42 & 0.13 & 8.68 & 51.51 & 0.12 \\
\hline C & 8.96 & 7.07 & 0.09 & 8.93 & 8.08 & 0.09 \\
\hline D & 7.55 & 92.2 & 0.08 & 7.25 & 92.56 & 0.08 \\
\hline$p$ value, ANOVA & 0.07 & 0.0001 & & 0.07 & 0.0001 & \\
\hline \multirow[t]{2}{*}{ Tukey post Hoc } & NA & $D>A, B, C$ & & NA & $D>B, A, C$ & \\
\hline & & $B>A, B>C$ & & & $B>A, B>C$ & \\
\hline $\begin{array}{l}\text { CFU = Colony fo } \\
\text { conventional GIC } \\
\text { with Amoxicillin }\end{array}$ & $\begin{array}{l}\text { ing units, } R \\
\text { jithout any } \\
\text { d Group an }\end{array}$ & $\begin{array}{l}\text { =the antibacterial ro } \\
\text { dition, (B) Group B-G } \\
\text { D) D - GIC with AgNP }\end{array}$ & $\begin{array}{l}\text { te, }(A) G r \\
\text { IC with } A \\
\text { s and } A m\end{array}$ & $\begin{array}{l}\text { A (control) } \\
\text { s, the Groul } \\
\text { cillin. }\end{array}$ & (C) $\mathrm{C}-\mathrm{GIC}$ & \\
\hline
\end{tabular}

Table 5: Comparison of compressive strength (MPa) of tested materials.

\begin{tabular}{|lllll|}
\hline Groups & Count & Mean (SD), & ANOVA F value & ANOVA p valur \\
\cline { 1 - 3 } Group A & 10 & $44.4 \pm 3.7$ & 3.12 & 0.07 \\
\cline { 1 - 2 } Group B & 10 & $45.6 \pm 5.3$ & & \\
\cline { 1 - 3 } Group C & 10 & $38.4 \pm 4.2$ & & \\
\cline { 1 - 2 } Group D & 10 & $45.3 \pm 6.3$ & & \\
\hline
\end{tabular}

Group A (control)- conventional GIC without any addition, Group B- GIC with AgNPs, Group C - GIC with Amoxicillin and Group D - GIC with AgNPs and Amoxicillin.

\section{Figures}



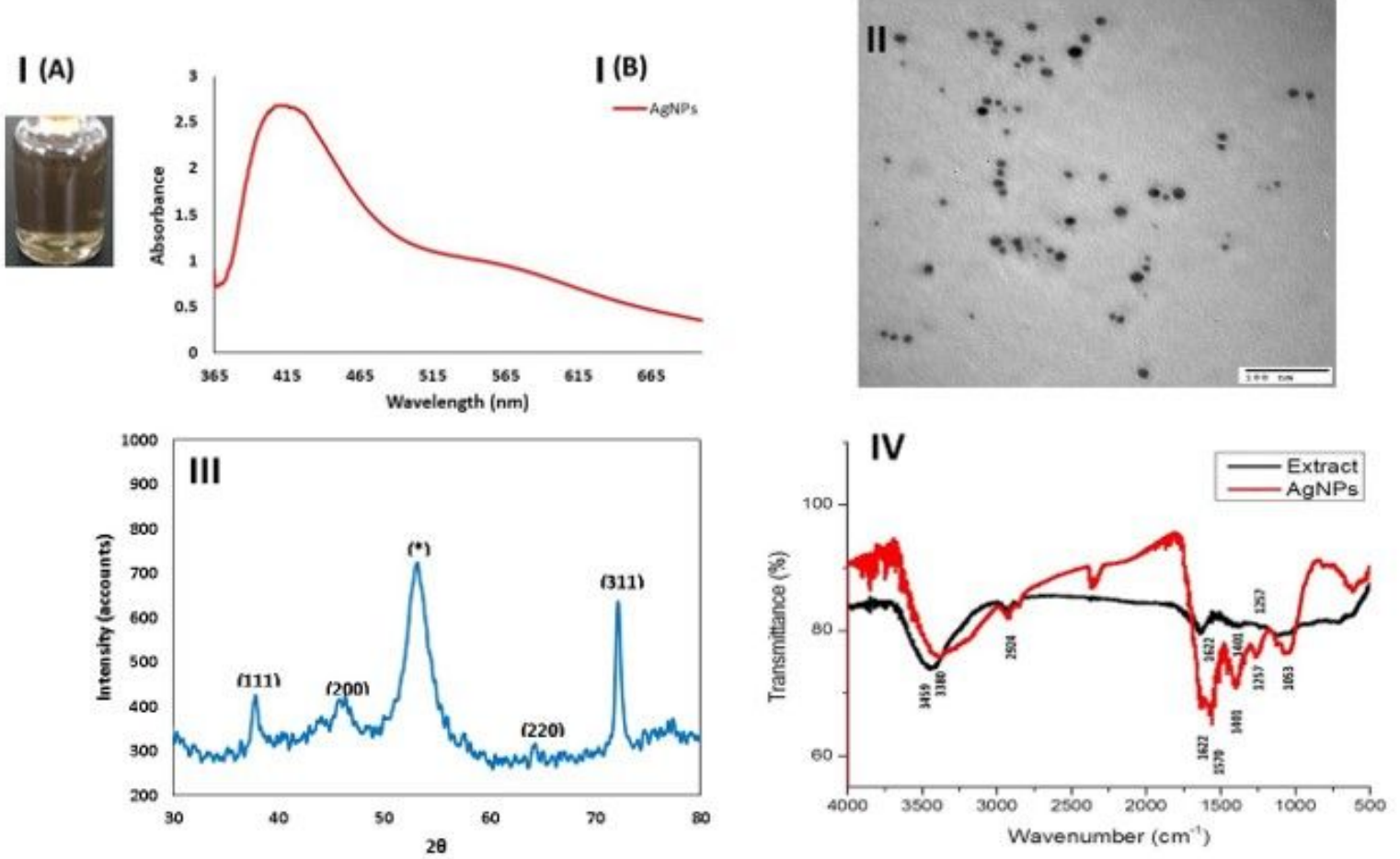

\section{Figure 1}

(I) Biosynthesis of AgNPs. Notes: Photograph showing the formation of AgNPs using Cupressus macrocarpa extract and visual observation of color changes (A). UV-vis spectra of AgNPs synthesized using Cupressus macrocarpa aqueous extract with $1 \mathrm{mM}$ AgNO3 (B). (II) TEM images of the synthesized AgNPs. (III) XRD patterns of the synthesized AgNPs with aqueous leaf extract of Cupressus macrocarpa. (IV) FTIR spectra of Cupressus macrocarpa extract (A) and the synthesized AgNPs (B). 

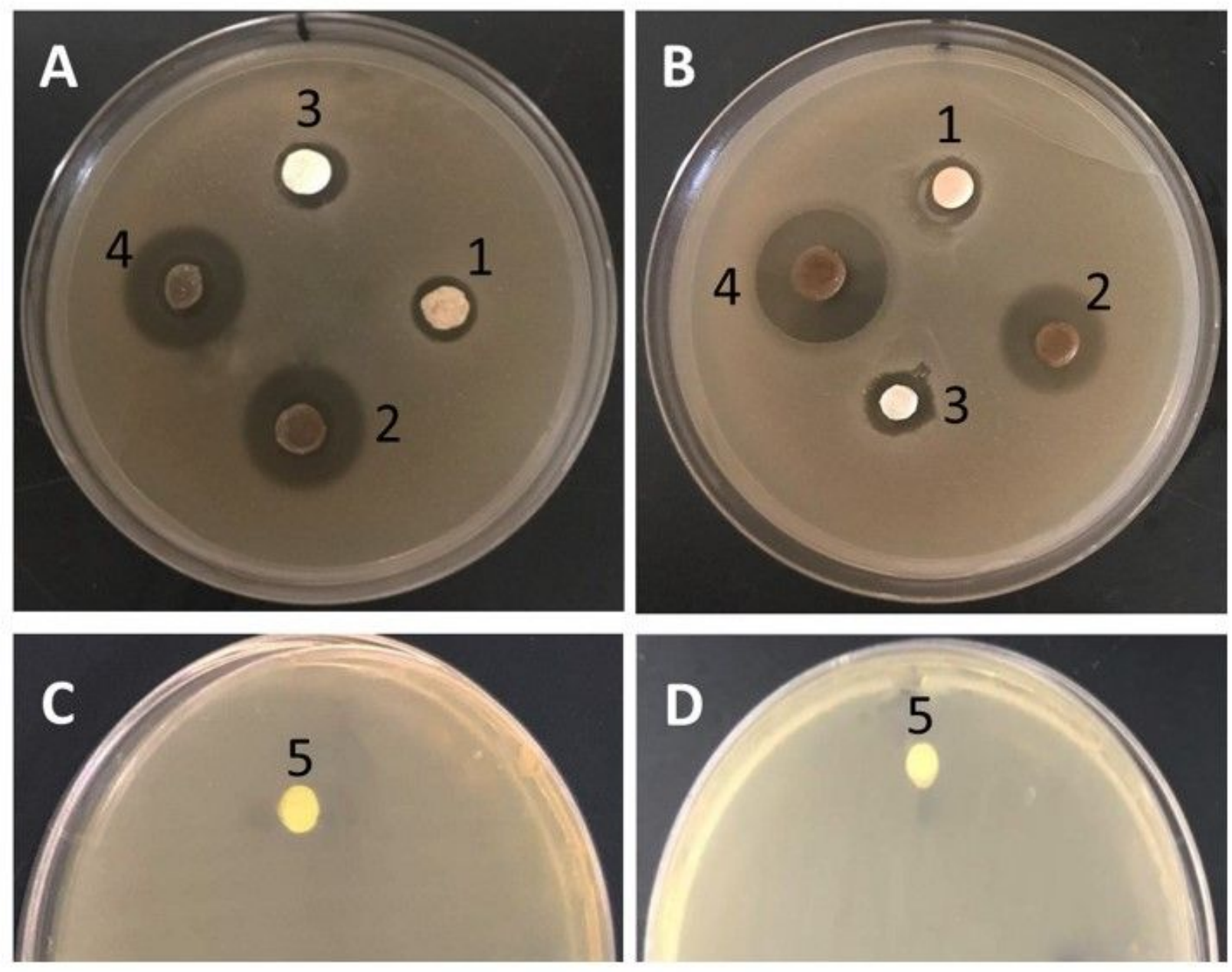

\section{Figure 2}

Antibacterial activity of GIC (1) or GIC-AgNPs (2), amoxicillin (3), GIC-AgNPs-amoxicillin (4) and Cupressus macrocarpa aqueous extract (5) against $S$. mutans ( $A$ and $C$ ) and $S$. aureus (B and $D)$ at $37^{\circ} \mathrm{C}$ for $24 \mathrm{~h}$. 


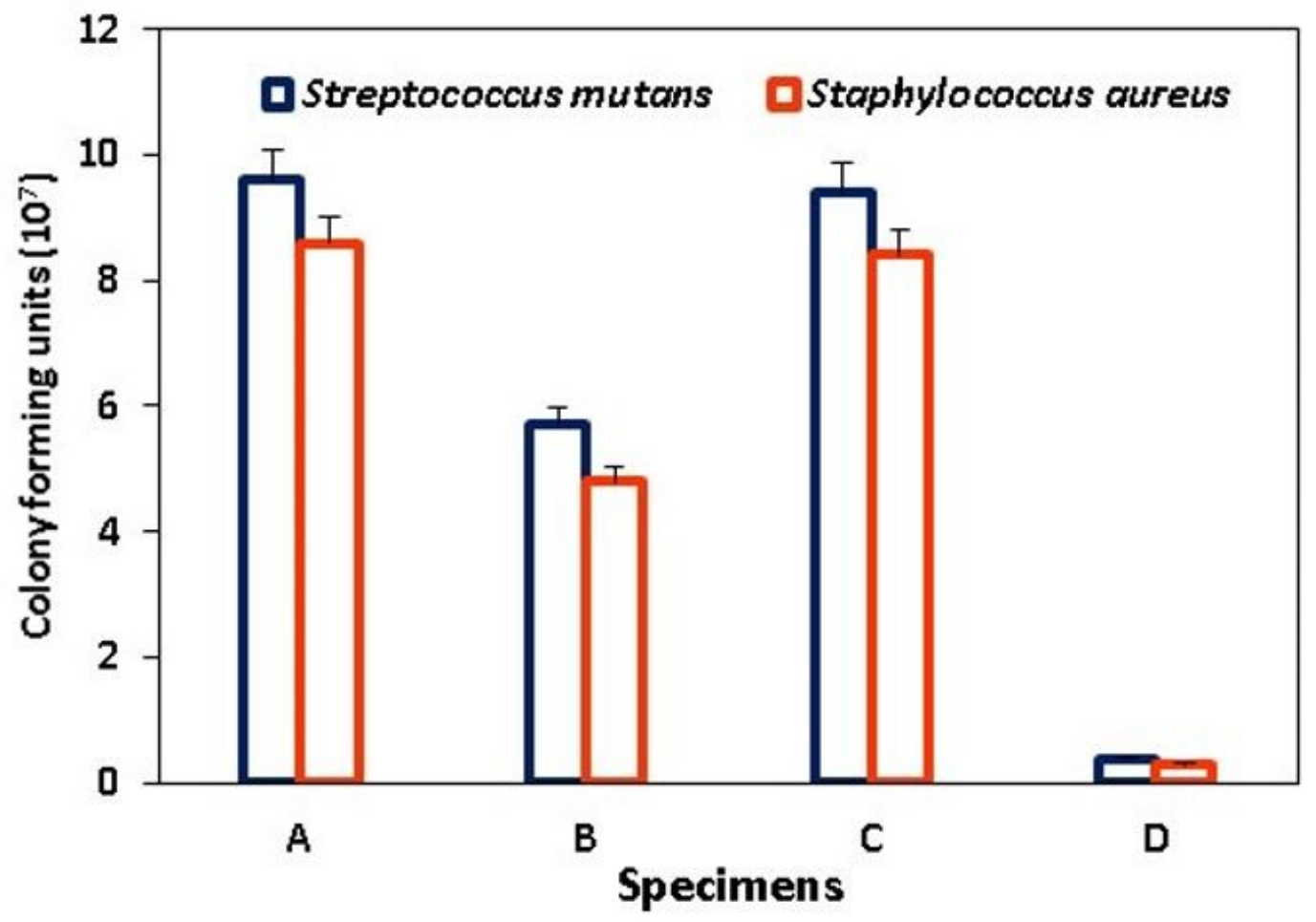

Figure 3

Colony forming units per disk for S. mutans and S. aureus to detect antibiofilm of (A) Group A (control)conventional GIC without any addition, (B) Group B- GIC with AgNPs, the Group, (C) C - GIC with Amoxicillin and Group and (D) D - GIC with AgNPs and Amoxicillin. 

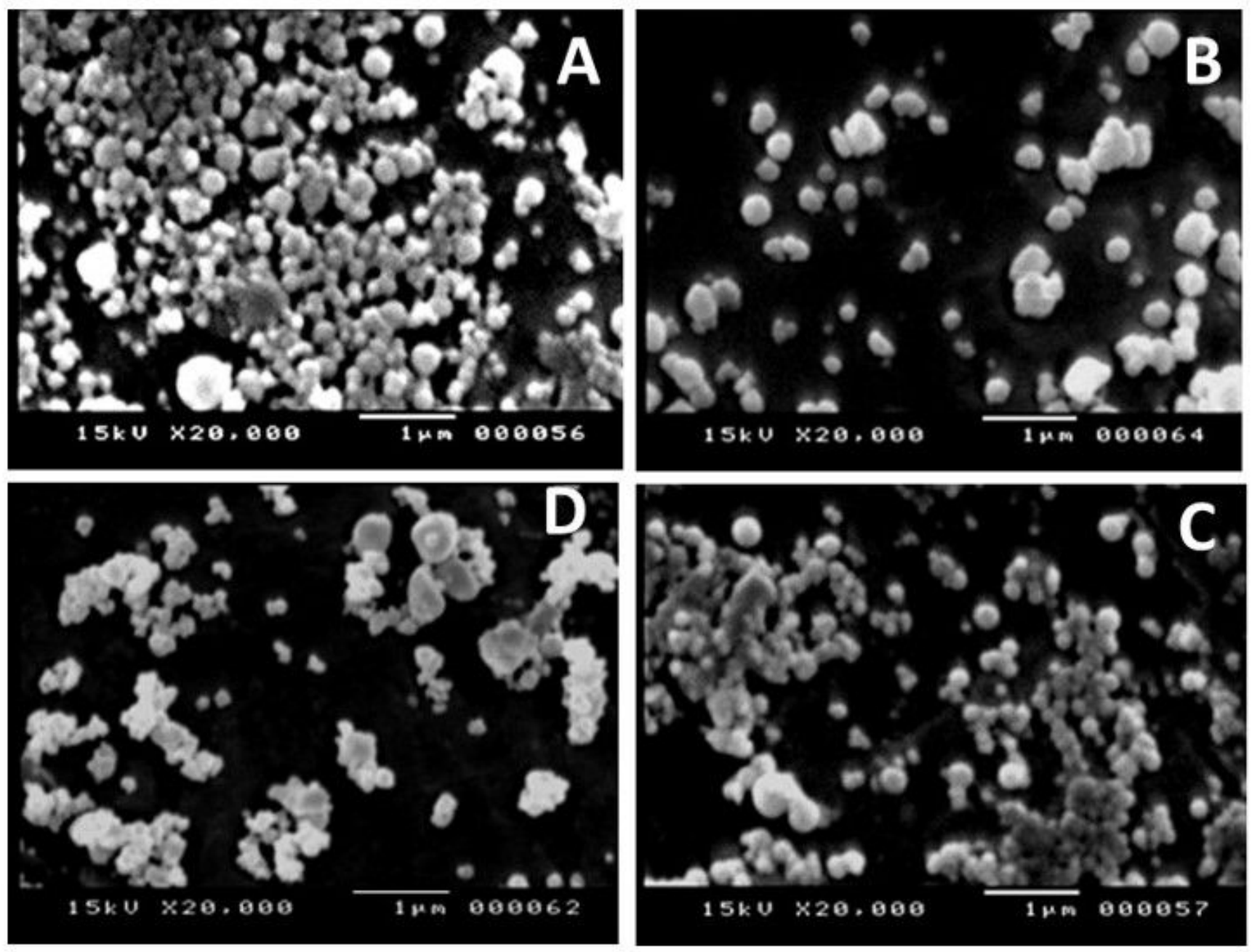

Figure 4

SEM images of S. aureus on group A (GIC), group B (GIC with AgNPs) group C (GIC with amoxicillin) group D (GIC with amoxicillin and AgNPs) after $24 \mathrm{hrs}$ of immersion in bacterial culture. 

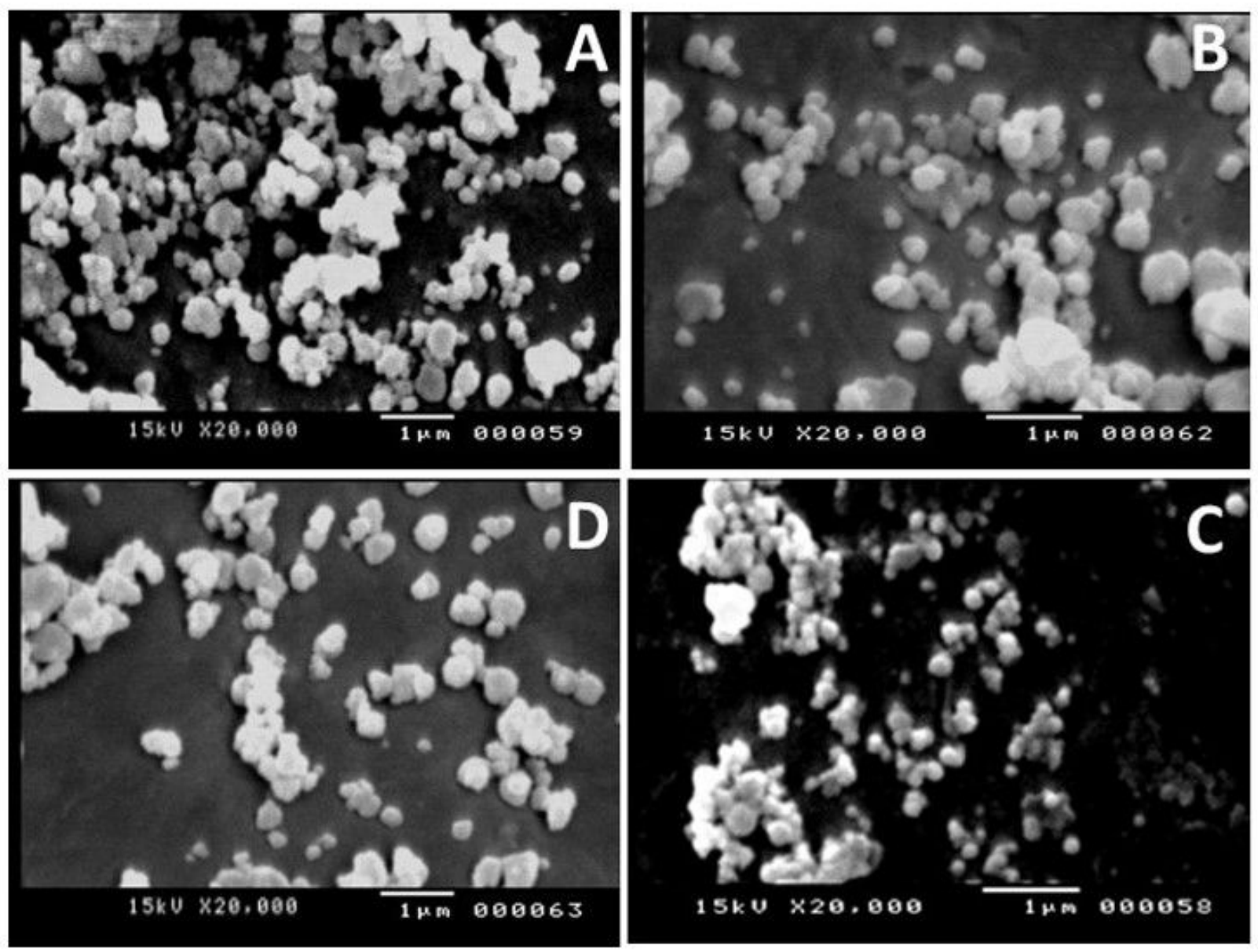

Figure 5

SEM images of S. mutans on group A (GIC), group B (GIC with AgNPs) group C (GIC with amoxicillin) group D (GIC with amoxicillin and AgNPs) after $24 \mathrm{hrs}$ of immersion in bacterial culture. 